\title{
Eldecalcitol effects on osteoblastic differentiation and function in the presence or absence of osteoclastic bone resorption
}

\author{
JIE BU $^{1,2}$, JUAN DU $^{1}$, LINA SHI $^{1}$, WEI FENG ${ }^{3}$, WEI WANG $^{1}$, JIE GUO $^{1}$, \\ TOMOKA HASEGAWA ${ }^{4}$, HONGRUI LIU ${ }^{1}$, XUXIA WANG ${ }^{2}$ and MINQI LI ${ }^{1}$
}

\begin{abstract}
Departments of ${ }^{1}$ Bone Metabolism and ${ }^{2}$ Oral Maxillofacial Surgery, School of Stomatology, Shandong University, Shandong Provincial Key Laboratory of Oral Tissue Regeneration; ${ }^{3}$ Department of Endodontics, Jinan Stomatological Hospital, Jinan, Shandong 250012, P.R. China; ${ }^{4}$ Department of Developmental Biology of Hard Tissue,

Graduate School of Dental Medicine, Hokkaido University, Sapporo 060-8586, Japan
\end{abstract}

Received September 6, 2018; Accepted May 17, 2019

DOI: $10.3892 /$ etm.2019.7784

\begin{abstract}
Eldecalcitol (ELD) is an active vitamin D3 analog, possesses anti-resorption properties and is an approved therapeutic drug for the treatment of osteoporosis in Japan. However, the effect of ELD on osteoblasts in a distinct cell microenvironment, including in the presence or absence of osteoclastic bone resorption, is undetermined. In the current study, the effect of bone resorption supernatant on the ELD-mediated regulation of viability, differentiation and receptor activator of NF- $\mathrm{KB}$ ligand/osteoprotegerin (RANKL/OPG) expression was assessed in MC3T3-E1 pre-osteoblast cells. The murine macrophage-like cell line RAW 264.7 was induced to differentiate into functional osteoblasts. Bone resorption supernatant was prepared by culturing osteoclast with a bovine cortical bone specimen. Mouse MC3T3-E1 cells were subsequently treated with ELD combined with differentiated osteoclast cell culture (OCS) or osteoclast bone resorption model supernatants. Cell counting kit- 8 , alkaline phosphatase (ALP) activity, reverse transcription-quantitative (RT-q) PCR and western blot analysis were used to assess cell viability, osteogenic activity and RANKL and OPG expression in MC3T3-E1 cells. The OCS and OCS + ELD treatment exhibited significantly increased MC3T3-E1 cell viability when compared with the control group. However, ELD, bone resorption culture
\end{abstract}

Correspondence to: Dr Xuxia Wang, Department of Oral Maxillofacial Surgery, School of Stomatology, Shandong University, Shandong Provincial Key Laboratory of Oral Tissue Regeneration, 44-1 Wenhua West Road, Jinan, Shandong 250012, P.R. China

E-mail:wxx@sdu.edu.cn

Dr Minqi Li, Department of Bone Metabolism, School of Stomatology, Shandong University, Shandong Provincial Key Laboratory of Oral Tissue Regeneration, 44-1 Wenhua West Road, Jinan, Shandong 250012, P.R. China

E-mail: liminqi@sdu.edu.cn

Key words: osteoblast, osteoclast, eldecalcitol, differentiation, receptor activator of $\mathrm{NF}-\mathrm{\kappa B}$ ligand, osteoprotegerin supernatant (BRS) and ELD + BRS treatments significantly decreased MC3T3-E1 cell viability. The results of ALP activity analysis, RT-qPCR and western blot analysis demonstrated that ELD treatment and OCS decreased the osteogenic markers (ALP and RUNX2), however, BRS increased them. All treatments enhanced the expression of RANKL and RANKL/OPG ratio. The results of the current study revealed that ELD inhibits osteoblastic differentiation in vitro. However, in the presence of BRS, which mimics the local bone microenvironment in vivo, the net effect on osteogenesis was positive. Furthermore, osteoclasts and bone matrix-derived factors increased the RANKL/OPG ratio, thereby potentiating osteoclastic activity.

\section{Introduction}

Bone remodeling has been described as a cycle that consists of three major consecutive overlapping phases: Resorption, reversal and formation (1). The bone systems homeostatic balance requires communication between osteoblasts and osteoclasts, which occurs at various stages of bone remodeling, and includes three modes: Direct, paracrine and cell-bone matrix (1). Through direct communication between osteoclasts and osteoblasts, membrane-bound ligands and receptors interact and initiate intracellular signaling. Gap junctions can also form between contact cells, allowing the passage of small water-soluble molecules (2). Communication between cells can also occur through diffusible paracrine factors, including growth factors, cytokines, chemokines and other small molecules, which are secreted by either cell type or acting on the other via diffusion (3). Growth factors and a variety of other molecules previously buried in the bone matrix have been demonstrated to be released by osteoclasts during bone resorption $(2,3)$. However, it is undetermined as to which of these cell communicators serves a key role in osteoblast activity.

$1 \alpha, 25$-dihydroxyvitamin $\mathrm{D}_{3}\left[1 \alpha, 25(\mathrm{OH})_{2} \mathrm{D}_{3}\right]$, the active form of vitamin $\mathrm{D}_{3}$, is a potent inducer of receptor activator of NF- $\mathrm{KB}$ ligand (RANKL), a key molecule that is secreted by osteoblasts in osteoclastogenesis (4). The expression of vitamin $\mathrm{D}$ receptors on osteoblast cells enables direct responses to vitamin $D_{3}$. The magnitude of effects in response to Vitamin $D_{3}$ 
is dependent on the presence of a number of factors in the cell microenvironment, including parathyroid hormone (PTH), calcium/phosphors level, transforming growth factor- $\beta 1$ (TGF- $\beta 1$ ) and insulin-like growth factor 1 (IGF-1) (5).

Despite vitamin $\mathrm{D}_{3}$ being successfully used in the management of conditions including psoriasis (6) and various cancer types (7), the use of vitamin $\mathrm{D}_{3}$ in the treatment of osteoporosis has been prevented due to its calcemic activity and the consensus that it is associated with osteoclastic bone resorption (8-10). Eldecalcitol (ELD), formerly known as ED-71, is an analog of $1 \alpha, 25-(\mathrm{OH})_{2} \mathrm{D}_{3}$ that includes a hydroxypropyloxy residue at the $2 \beta$ position (11). ELD was previously developed to increase the inhibitory effect on bone resorption and was approved in Japan as a therapeutic drug for the treatment of osteoporosis in 2011 (12-14). It has been previously reported that ELD lowered the biochemical and histological parameters of bone resorption in a ovariectomized rat model of osteoporosis (15). These aforementioned effects were observed without sustained hypercalcemia or hypercalciuria (12).

Previous studies have demonstrated that TGF- $\beta$ and IGF-1, which are released from the bone matrix during osteoclastic bone resorption, serve an important role in osteoblast activities including receptor activator of NF- $\mathrm{NB}$ ligand (RANKL) expression and cell migration (16-18). The present study aimed to determine the role of proteins, which are released by bone slices during osteoclastic bone resorption, in the regulation of osteoblast activity. The current study also provides additional data to understand how ELD affects osteoblasts in a distinct cell microenvironment, for example, in the presence or absence of osteoclastic bone resorption. Osteoblast cell culture models were established in vitro, with differentiated osteoclast cell culture supernatants (OCS) or bone resorption culture supernatant (BRS). Osteoblastic induction was performed using MC3T3-E1 pre-osteoblast cells and the viability, differentiation and RANKL/osteoprotegerin (OPG) expression of osteoblast cells was determined.

\section{Materials and methods}

Pre-osteoclast culture and osteoclastic induction. Murine RAW264.7 monocytic cells were purchased from the Type Culture Collection of the Chinese Academy of Sciences and cultured in $\alpha$-minimum essential medium ( $\alpha$-MEM; Gibco; Thermo Fisher Scientific, Inc.) supplemented with 10\% FBS (Gibco; Thermo Fisher Scientific, Inc.), $10 \mathrm{U} / 1$ penicillin and $100 \mathrm{mg} / \mathrm{l}$ streptomycin at $37^{\circ} \mathrm{C}$ in a humidified atmosphere containing $5 \% \mathrm{CO}_{2}$. Recombinant soluble mouse RANKL and macrophage colony-stimulating factor (M-CSF) were purchased from R\&D Systems, Inc. for use in osteoclast differentiation. The cells were seeded in six-well plate $\left(5 \times 10^{5}\right.$ cells/well) or 24 -well plate $\left(3 \times 10^{4}\right.$ cells/well $)$ and cultured at $37^{\circ} \mathrm{C}$ for 6 days in $\alpha$-MEM supplemented with $10 \%$ FBS, $30 \mathrm{ng} / \mathrm{ml} \mathrm{M-CSF}$ and $50 \mathrm{ng} / \mathrm{ml}$ RANKL. The culture medium was collected on day 6 .

Establishment of bone resorption model. Cortical bone slices $(5 \times 5 \mathrm{~mm})$ of fresh bovine femur slices $(0.1 \mathrm{~mm})$ were purchased from the Immunodiagnostic Systems, Ltd. (cat. no. DT-1BON1000-96) and used to create the bone resorption model according to the protocol described previously $(19,20)$.
RAW 264.7 cells were seeded into 24 -well plates ( $3 \times 10^{4}$ cells/well) and cultured in $\alpha$-MEM supplemented with $10 \% \mathrm{FBS}, 10 \mathrm{U} / 1$ penicillin and $100 \mathrm{mg} / \mathrm{l}$ streptomycin with the prepared cortical bone slices. After $24 \mathrm{~h}$, cells were treated with $30 \mathrm{ng} / \mathrm{ml} \mathrm{M-CSF}$ and $50 \mathrm{ng} / \mathrm{ml} \mathrm{RANKL}$ at $37^{\circ} \mathrm{C}$ for 6 days (21). The culture medium was replaced every 2 days and was collected on day 6 . Supernatants were centrifuged $(400 \mathrm{x} \mathrm{g}$ $4^{\circ} \mathrm{C}$ for $10 \mathrm{~min}$ ), filtered through a $0.22 \mathrm{~mm}$ polyethersulfone membrane filter (EMD Millipore) and stored at $-20^{\circ} \mathrm{C}$.

Osteoblast cell culture. Murine MC3T3-E1 pre-osteoblast cells were purchased from the Type Culture Collection of the Chinese Academy of Sciences. MC3T3-E1 cells were cultured in $\alpha$-MEM (Gibco; Thermo Fisher Scientific, Inc.) supplemented with $10 \% \mathrm{FBS}, 10 \mathrm{U} / 1$ penicillin and $100 \mathrm{mg} / \mathrm{l}$ streptomycin. Six groups were formed: i) MC3T3-E1 that were cultured with OCS; ii) MC3T3-E1 that were cultured with BRS; iii) MC3T3-E1 that were cultured with OCS + ELD and iv) MC3T3-E1 that were cultures with BRS + ELD; v) MC3T3-E1 that were cultured with ELD; and vi) CON group. Exponentially growing cells were plated into six-well plates $\left(6 \times 10^{3}\right.$ cells/well) for reverse transcription-quantitative PCR (RT-qPCR) and western blot analysis. After incubation at $37^{\circ} \mathrm{C}$ for $24 \mathrm{~h}$, cells were transferred to a medium containing $75 \%$ (v/v) $\alpha$-MEM (Gibco; Thermo Fisher Scientific, Inc.) supplemented with $10 \% \mathrm{FBS}, 10 \mathrm{U} / 1$ penicillin, $100 \mathrm{mg} / 1$ streptomycin and $25 \%(\mathrm{v} / \mathrm{v})$ OCS or BRS. ELD $\left(10^{-7} \mathrm{M}\right)$ was added to the ELD group (Chugai Pharmaceutical Co., Ltd.).

Cell viability assay. The MC3T3-E1 pre-osteoblast cells were harvested and seeded into 96 well plates $\left(1 \times 10^{4}\right.$ cells/well $)$ with a total volume of $200 \mu \mathrm{l}$ culture medium. Cells were incubated for 24,48 and $72 \mathrm{~h}$ at $37^{\circ} \mathrm{C}$. After the cells were treated for the indicated times, Cell Counting Kit-8 (MedChem Express) was used $(20 \mu \mathrm{l} /$ well $)$ and cells were incubated for $3 \mathrm{~h}$ at $37^{\circ} \mathrm{C}$. Subsequently, absorbance at $450 \mathrm{~nm}$ was read for all plates using an automated microplate spectrophotometer (Bio Rad Laboratories, Inc.). Each experiment was repeated at least three times.

Tartrate-resistant acid phosphatase (TRAP) staining. RAW 264.7 cells were seeded into 24 -well plates and cultured in $\alpha$-MEM supplemented with aforementioned stimuli for 6 days. Cells were fixed with $4 \%$ paraformaldehyde for at least $15 \mathrm{~min}$ at room temperature and stained for TRAP using a TRAP-staining solution containing $0.1 \mathrm{M}$ sodium acetate $(\mathrm{pH} 5.0)$ and $0.01 \%$ naphthol AS-MX phosphate (Sigma-Aldrich; Merck KGaA) as a substrate and $0.03 \%$ red violet LB salt (Sigma-Aldrich; Merck KGaA) as a stain for the reaction product in the presence of $50 \mathrm{mM}$ sodium tartrate for $15 \mathrm{~min}$ at $37^{\circ} \mathrm{C}$. Staining was observed by light microscopy (magnification, x100 and x400; Olympus Corporation). Cell nuclei were counterstained with hematoxylin for $2 \mathrm{~min}$ at room temperature. Multinucleated TRAP-positive cells with at least three nuclei were scored as osteoclasts (22).

$R T$ - $q P C R$. Total RNA was extracted from RAW 264.7 cells using TRIzol reagent (Invitrogen; Thermo Fisher Scientific, Inc.). cDNA was synthesized using PrimeScript ${ }^{\mathrm{TM}}$ RT reagent kit (Takara Bio, Inc.) according to the manufacturer's protocol. 
Alkaline phosphatase (ALP), RUNX2, RANKL and OPG mRNA expression were assessed on days 1, 3 and 7 using qPCR that was performed using $1 \mu \mathrm{l}$ cDNA template in a $10 \mu$ l total volume with the TB Green ${ }^{\circledR}$ Premix Ex Taq ${ }^{\mathrm{TM}}$ (Takara Bio, Inc.) using $\mathrm{MyiQ}^{\mathrm{TM}}$ Single-Color Real-Time PCR Detection System (Bio-Rad Laboratories, Inc.). The thermocycling conditions used were: Initial denaturation for $10 \mathrm{sec}$ at $95^{\circ} \mathrm{C}$, followed by 40 cycles of $5 \mathrm{sec}$ at $95^{\circ} \mathrm{C}, 31 \mathrm{sec}$ at $58^{\circ} \mathrm{C}$ and $30 \mathrm{sec}$ at $72^{\circ} \mathrm{C}$. The data were collected at $72^{\circ} \mathrm{C}$ in each cycle. The mRNA value was normalized to that of the housekeeping gene GAPDH. The results are presented as the relative gene expression. The fold-change in gene expression relative to the control was calculated using the $2^{-\Delta \Delta C q}$ method (23) with GraphPad Prism software (version 6.0; GraphPad Software, Inc.). The primer sequences are presented in Table I.

Western blot analysis. MC3T3-E1 cells were harvested on days 1, 3 and 7 and lysed using RIPA lysis buffer (Beijing ComWin Biotech Co., Ltd.). Following measurement of protein concentration using a Bicinchoninic Acid assay kit (Beyotime Institute of Biotechnology), the protein samples $(50 \mu \mathrm{g})$ were mixed with $1 / 4$ volume of $5 X$ SDS loading buffer and heated at $95^{\circ} \mathrm{C}$ for $5 \mathrm{~min}$. Following separation by $10-15 \%$ SDS-PAGE, proteins were transferred to PVDF membranes. The membranes were blocked with 5\% BSA diluted in TBS supplemented with $0.1 \%$ Tween-20 at room temperature for $1 \mathrm{~h}$. Western blot analysis was performed using: Rabbit anti-ALP antibody (1:1,000; cat. no. ab83259; Abcam), mouse anti-RUNX2 antibody (1:1,000; cat. no. ab76956; Abcam), rabbit anti-RANKL antibody (1:1,000; cat. no. sc-9073; Santa Cruz Biotechnology, Inc.), rabbit anti-OPG antibody (1:1,000; cat. no. ab73400; Abcam) and mouse anti-GAPDH (1:2,000; cat. no. ab8245; Abcam), overnight at $4^{\circ} \mathrm{C}$. The secondary antibodies used were horseradish peroxidase (HRP)-conjugated goat anti-rabbit IgG (1:2,000; cat. no. \#14708; Cell Signaling Technology, Inc.) for ALP, RANKL and OPG and HRP-conjugated rabbit anti-mouse $\operatorname{IgG}(1: 1,000$; cat. no. \#58802; Cell Signaling Technology, Inc.) for GAPDH and RUNX2, at room temperature for $1 \mathrm{~h}$. Protein bands were visualized using an enhanced chemiluminescence reagent (Millipore; Merck KGaA) and western blot images were captured using a FluorChem E System (ProteinSimple) and quantified using ImageJ software (version 1.41; National Institute of Health).

Statistical analysis. The data are expressed as the mean \pm standard deviation. All experiments were performed in triplicate. GraphPad Prism 6.0 software was used to analyze the obtained data (GraphPad Software, Inc.). A one-way ANOVA was used for multiple group comparisons and the mean value of each group was compared using the Student-Newman-Keuls test. $\mathrm{P}<0.05$ was considered to indicate a statistically significant result.

\section{Results}

TRAP staining indicates that RAW 264.7 cells could be differentiated into functioning osteoclasts. Since the identification of the gene encoding RANKL, a cocktail of soluble forms of RANKL and M-CSF (also known as CSF-1) has been used to generate osteoclast-like cells in vitro in the absence
Table I. Sequences of primers used for reverse transcription-quantitative PCR.

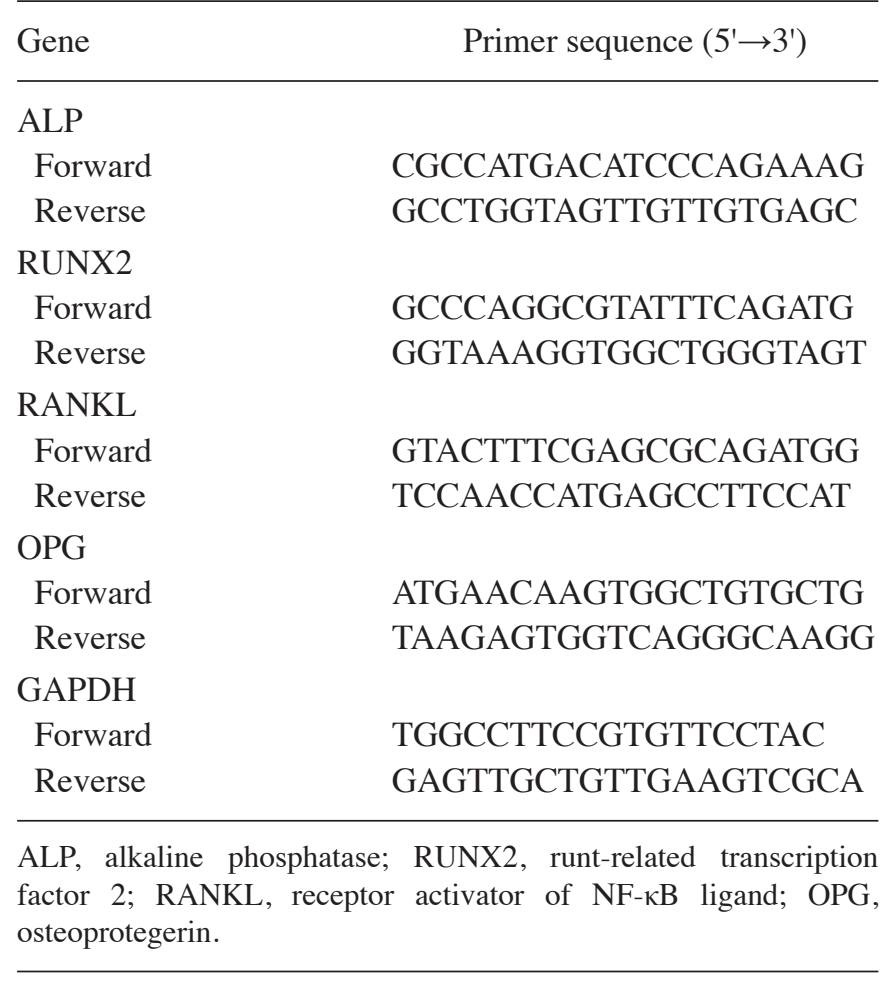

of osteoblasts, simplifying the analysis of osteoclast differentiation (24). The results of the current study observed that $50 \mathrm{ng} / \mathrm{ml}$ RANKL could stimulate RAW264.7 cells to develop into TRAP-positive cells after 1 day and multinucleated cells after 3-4 days. During RANKL-induced differentiation, RAW264.7 cells started to undergo the characteristic morphological changes after 3 days with increasing cell-cell fusion into large and multinucleated cells. TRAP staining of RAW264.7 cultured without stimuli (Fig. 1A) or with $30 \mathrm{ng} / \mathrm{ml} \mathrm{M-CSF}$ and $50 \mathrm{ng} / \mathrm{ml}$ RANKL (Fig. 1B) were observed on day 6 . An increase in TRAP staining and cell fusion were observed in the RANKL/M-CSF-induced differentiation group compared with the control group on day 6. TRAP-positive multinucleated cells (MNCs) containing three or more nuclei were counted as osteoclasts.

Osteoclast culture supernatant, osteoclast bone resorption supernatant and ELD regulate MC3T3-E1 pre-osteoblast viability and ALP activity. The OCS and OCS + ELD treatment significantly increased MC3T3-E1 cell viability after 48 and $72 \mathrm{~h}$ compared with the control group (CON), whilst ELD exerted no significant effects on MC3T3-E1 cell viability compared with CON (Fig. 2A). However, BRS alone, ELD + BRS and ELD alone significantly reduced MC3T3-E1 cell viability at $24 \mathrm{~h}$, when compared with CON (Fig. 2B). ALP activity is a marker of early stage osteoblast differentiation (25). OCS and ELD significantly reduced ALP activity, and combined OCS + ELD treatment exerted an additional inhibitory effect; however, no significant difference was observed between the OCS and ELD alone groups (Fig. 2C). BRS enhanced MC3T3-E1 cell ALP activity, and this increased effect was also present in the BRS-ELD treatment. However, 


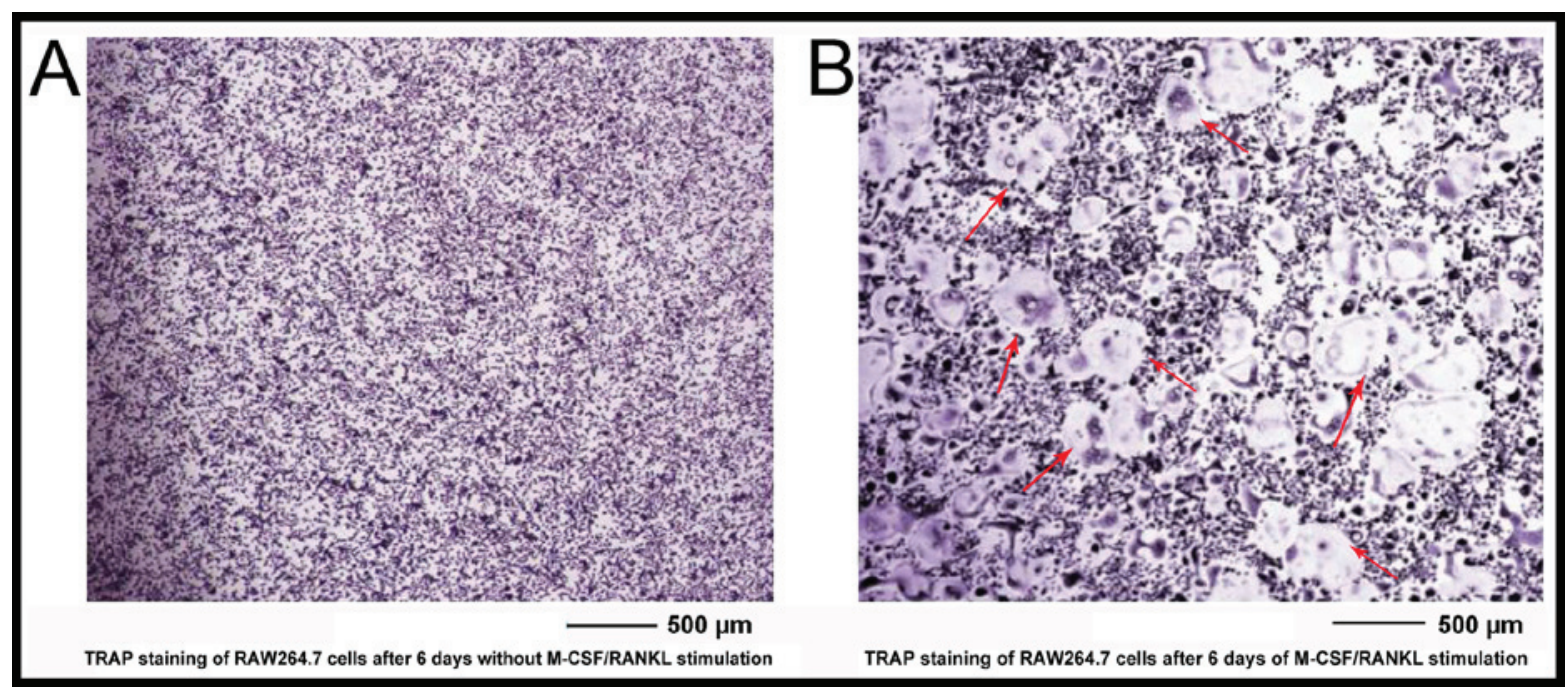

Figure 1. TRAP staining of RAW264.7 cell differentiation on day 6. (A and B) TRAP staining of RAW264.7 cultured (A) without stimuli and (B) with $30 \mathrm{ng} / \mathrm{ml}$ M-CSF and $50 \mathrm{ng} / \mathrm{ml}$ RANKL for 6 days. Multinucleated TRAP-positive cells with at least three nuclei were scored as osteoclasts. Red arrows indicate differentiated osteoclasts. TRAP, tartrate-resistant acid phosphatase; M-CSF, macrophage colony-stimulating factor; RANKL, receptor activator of NF- $\kappa$ B ligand.

A

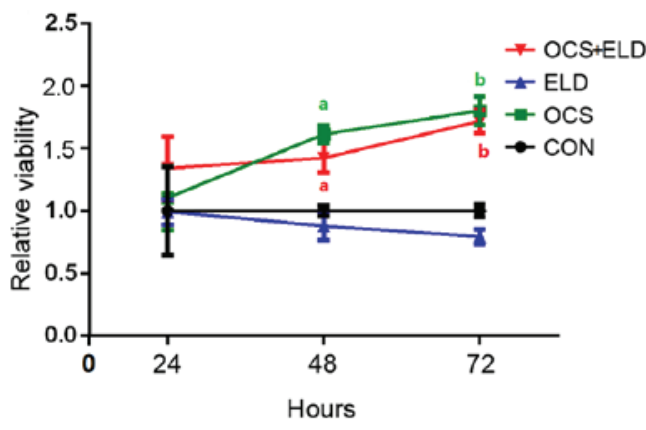

C

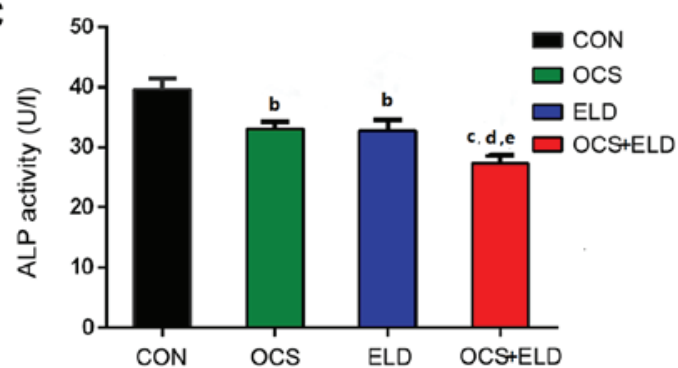

B

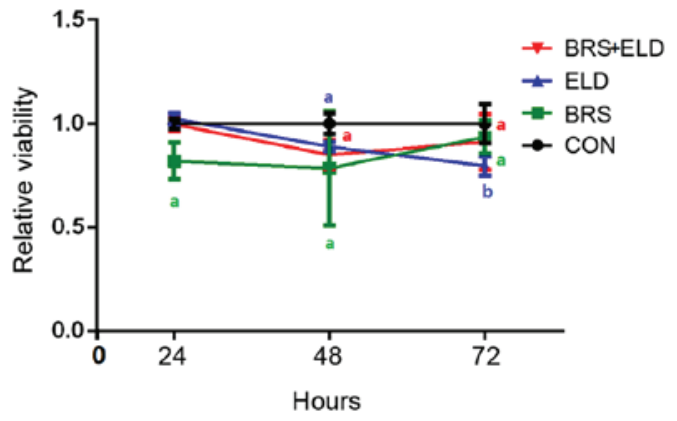

D

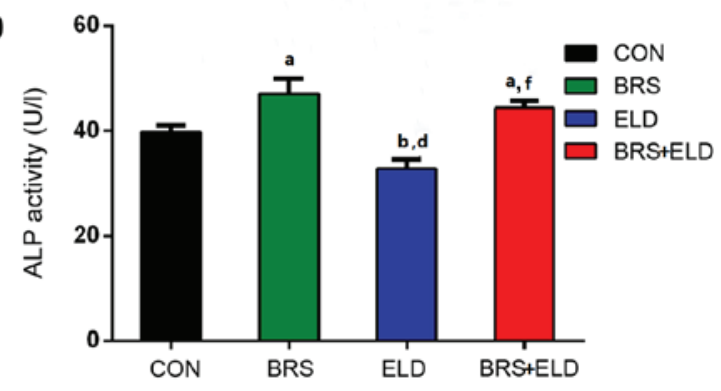

Figure 2. Osteoclasts culture supernatant, osteoclasts bone resorption supernatant and ELD distinctly regulated MC3T3-E1 pre-osteoblast viability and ALP activity. Relative cell viability of MC3T3-E1 cells treated with (A) OCS + ELD, ELD and OCS and (B) BRS + ELD, ELD and BRS with the associated controls ALP activity in MC3T3-E1 cells treated with (C) OCS + ELD, ELD and OCS and (D) BRS + ELD, ELD and BRS with the associated controls. ${ }^{\mathrm{P}}<0.05$, ${ }^{b} \mathrm{P}<0.01$ and ${ }^{\mathrm{c}} \mathrm{P}<0.001$ vs. CON; ${ }^{\mathrm{d}} \mathrm{P}<0.01$ vs. OCS or BRS; ${ }^{e} \mathrm{P}<0.05$ and ${ }^{\mathrm{f}} \mathrm{P}<0.001$ vs. ELD. ELD, eldecalcitol; ALP, alkaline phosphatase; OCS, differentiated osteoclast cell culture supernatants; BRS, bone resorption culture supernatant; CON, control.

ELD treatment decreased ALP activity when compared with the CON group (Fig. 2D).

Osteoclast culture supernatant and ELD reduces osteogenic marker expression and increases $R A N K L / O P G$ ratio. ALP and RUNX2 mRNA expression was detected in MC3T3-E1 cells cultured with OCS, ELD or OCS + ELD. The results of RT-qPCR demonstrated that ELD and OCS treatment reduced the expression of osteogenic markers (ALP and RUNX2) in MC3T3-E1 cells when compared with the control group on days 1, 3 and 7; and their combination exerted an additional inhibitory effect on day 3 (Fig. 3A and B). ELD, OCS and ELD + OCS all enhanced RANKL expression and reduced OPG on days 1,3 and 7, resulting in an increased RANKL/OPG ratio in MC3T3-E1 cells (Fig. 3C-E). However, no difference was observed between the ELD and CON groups on days 1, 3 or 7 (Fig. 3C-E). This observation suggests that ELD may affect osteoblasts through the medium secreted by osteoclasts, rather than directly acting on osteoblasts.

Western blot analysis was performed to measure RUNX2, RANKL and OPG expression on days 1, 3 and 7. The results exhibited similar patterns with that of mRNA expression, in 

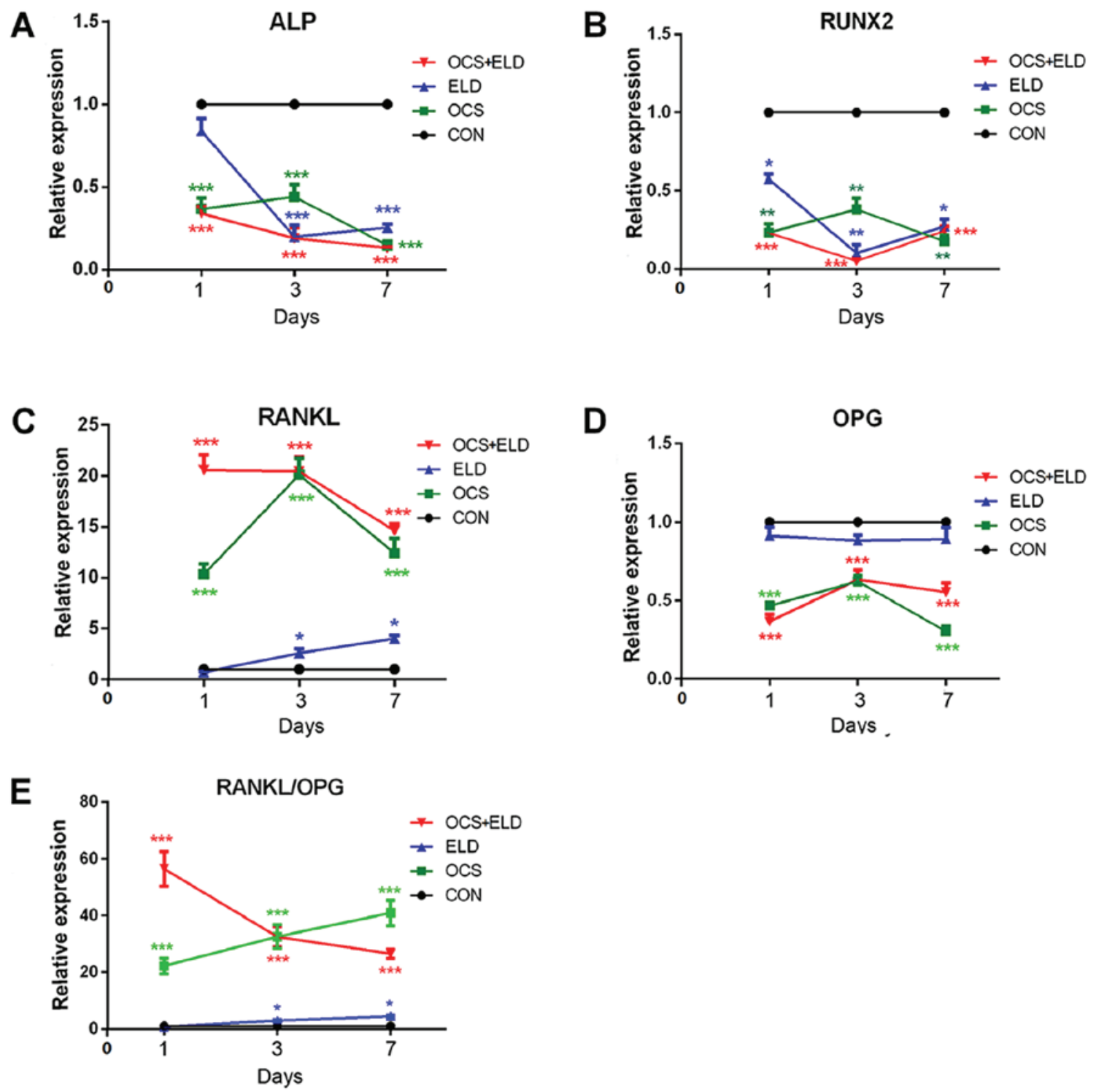

Figure 3. mRNA expression of pre-osteoblasts osteogenic markers and RANKL/OPG expression in MC3T3-E1 cells treated with osteoclasts culture supernatant and ELD. Reverse transcription-quantitative PCR analysis of (A) ALP, (B) RUNX2, (C) RANKL, (D) OPG and (E) RANKL/OPG expression in MC3T3-E1 cells cultured in the presence of OCS or ELD and OCS + ELD. ${ }^{*} \mathrm{P}<0.05,{ }^{* *} \mathrm{P}<0.01$ and ${ }^{* * *} \mathrm{P}<0.001$ vs. CON. RANKL, receptor activator of NF- $\mathrm{kB}$ ligand; OPG, osteoprotegerin; ELD, eldecalcitol; ALP, alkaline phosphatase; RUNX2, runt-related transcription factor 2; OCS, differentiated osteoclast cell culture supernatants; CON, control.

that RUNX2 expression was significantly decreased in ELD and OCS treatment groups when compared with CON on days 1, 3 and 7 (Fig. 4A and B). In addition, enhanced RANKL expression (Fig. 4A and $\mathrm{C}$ ), decreased OPG expression on days 1 and 3 (Fig. 4A and D) and increased the RANKL/OPG ratio (Fig. 4E) were also observed in the ELD and OCS treatment groups compared with CON. These results indicated that cells cultured with OCS + ELD reduced RUNX2 expression and increased the RANKL/OPG ratio.

ELD induces the inhibition of osteogenic marker expression and increases the RANKL/OPG ratio and these actions are reversed by co-culture with bone resorption supernatant. ELD significantly inhibited ALP and RUNX2 mRNA expression in MC3T3-E1 cells (Fig. 5A and B). However, BRS greatly increased the mRNA expression of osteogenic markers ALP and RANKL when compared with CON (Fig. 5A and C). This promotive effect was also exhibited by the BRS + ELD group (Fig. 5A-C), while ELD showed a significant inhibitory effect on ALP activity on days 3 and 7 and on RUNX2 expression on days 1, 3 and 7 when compared with $\mathrm{CON}$ (Fig. 5A and B). BRS promoted RANKL expression when compared with CON on days 1, 3 and 7. However, for the ELD group this was evident only on day 7. Compared with the ELD group, BRS treatment potentiated RANKL expression over 15-fold on day 3. An additional promotive effect on RANKL expression was exhibited by the ELD + BRS group on days 1 and 7 (Fig. 5C). Furthermore, no significant differences were observed in the mRNA expression levels of OPG in the BRS or BRS + ELD groups when compared with CON group, whilst the RANKL/OPG ratio was increased in the BRS and BRS + ELD groups due to the increased RANKL expression on days 1,3 and 7 compared with the CON group (Fig. 5D and E). The results of the western blot analysis were almost in concordance 

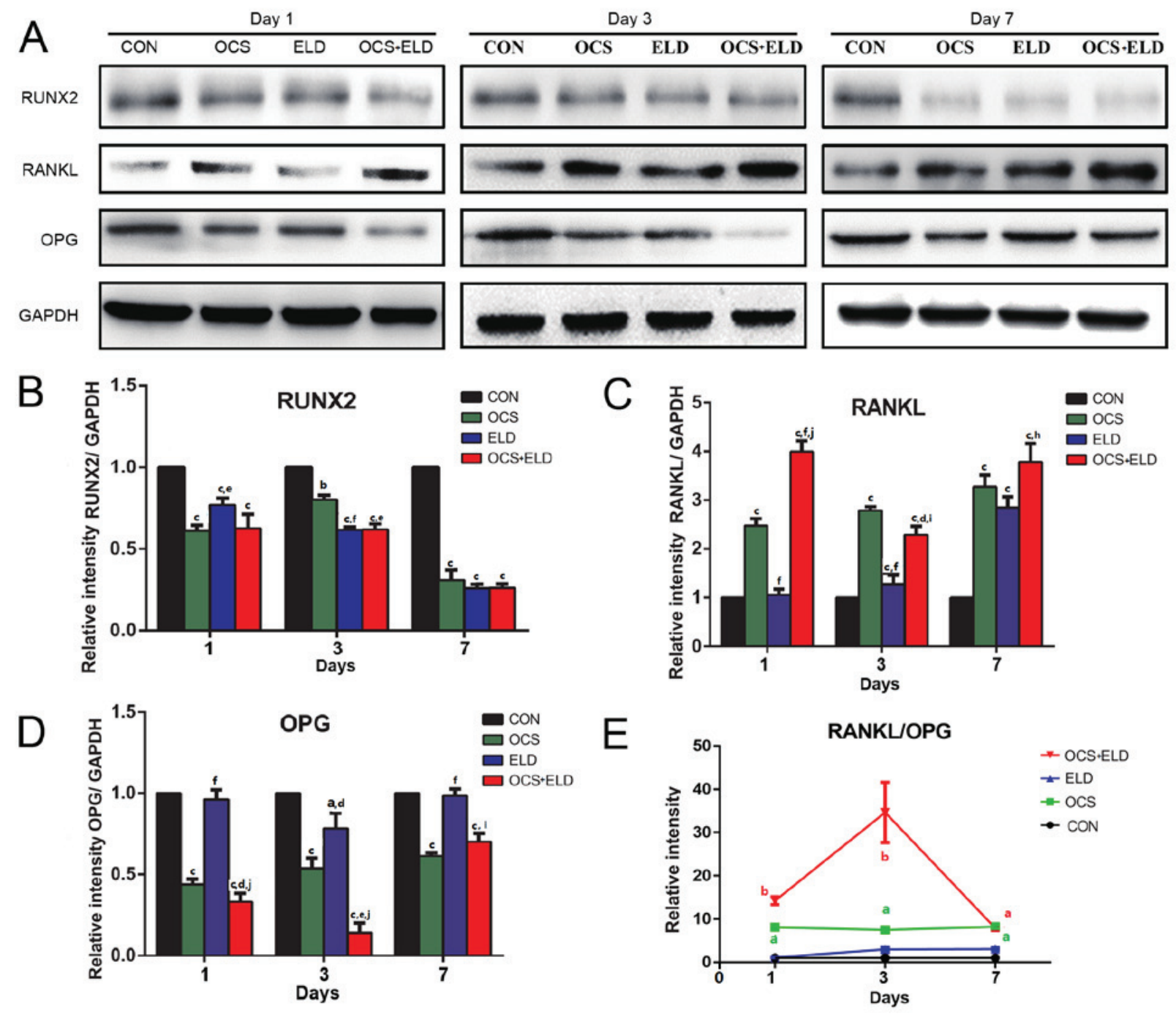

Figure 4. Western blot analysis of osteoclasts culture supernatant and ELD on the MC3T3-E1 pre-osteoblasts osteogenic markers and RANKL/OPG expressions. (A) western blot analysis of (A) RUNX2, RANKL, OPG and GADPH expression with subsequent quantification of (B) RUNX2, (C) RANKL, (D) OPG and (E) RANKL/OPG in MC3T3-E1 cells treated with OCS, ELD or OCS + ELD. ${ }^{\mathrm{a}} \mathrm{P}<0.05,{ }^{\mathrm{b}} \mathrm{P}<0.01$ and ${ }^{\mathrm{C}} \mathrm{P}<0.001$ vs. CON; ${ }^{\mathrm{d}} \mathrm{P}<0.05$, ${ }^{\mathrm{e}} \mathrm{P}<0.01,{ }^{\mathrm{f}} \mathrm{P}<0.001$ vs. OCS; ${ }^{h} \mathrm{P}<0.05,{ }^{\mathrm{P}}<0.01$ and ${ }^{\mathrm{j}} \mathrm{P}<0.001$ vs. ELD. ELD, eldecalcitol; RANKL, receptor activator of NF- $\mathrm{kB}$ ligand; OPG, osteoprotegerin; RUNX2, runt-related transcription factor 2; OCS, differentiated osteoclast cell culture supernatants; CON, control.

with the mRNA expression data (Fig. 6A). The BRS group exhibited upregulated RUNX2 expression and ELD exhibited downregulated RUNX2 expression when compared with the CON group on days 1,3 and 7. The ELD + BRS group upregulated the RUNX2 expression (Fig. 6B), and treatments with ELD alone, BRS alone and ELD + BRS all enhanced RANKL expression (Fig. 6C) and RANKL/OPG ratio in MC3T3-E1 cells on days 1, 3 and 7 (Fig. 6E). Significantly different values were exhibited by the BRS, BRS + ELD were observed on day 7 for OPG expression compared with CON (Fig. 6D). The aforementioned results demonstrated that ELD induced the inhibition of osteogenic marker expression and increased the RANKL/OPG ratio, and these effects could be reversed by co-culture with osteoclast BRS.

\section{Discussion}

Bone remodeling is based on the communication between osteoblasts and osteoclasts and is a local process that can occur anywhere on the bone surface throughout the lifespan of humans (26). By removing old or damaged bone and replacing it with new, stronger bone, the structural integrity and strength of the bone are maintained. Osteoblasts serve a pivotal role in bone metabolism but also control and regulate the formation and activity of osteoclasts (27). Osteoclasts, which develop from hematopoietic cells of the monocyte-macrophage lineage, are responsible for bone resorption that subsequently triggers the differentiation and activation of osteoblasts (28). It has been shown that osteoblast and osteoclast can communicate with each other through direct cell-cell, cytokine or cell-bone matrix contact (3).

A previous study assessed c-fos deficient mice with no osteoclasts and c-Src deficient mice with dysfunctional osteoclasts, and it was histologically indicated that the presence of osteoclasts is essential for osteoblastic activity (29). However, it is difficult to determine how molecules secreted by osteoclasts and/or released by them from the bone matrix affect 
A

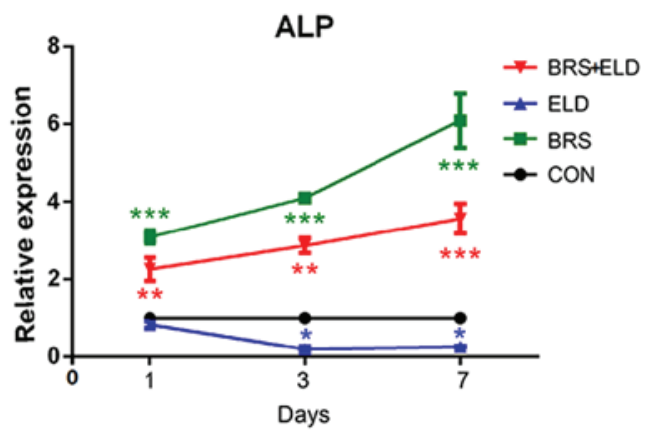

C

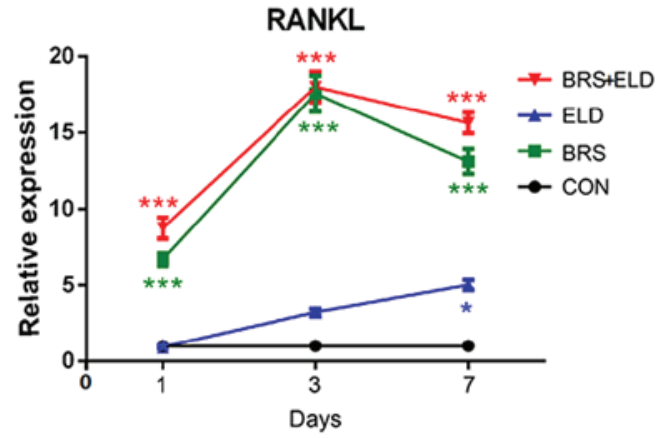

E

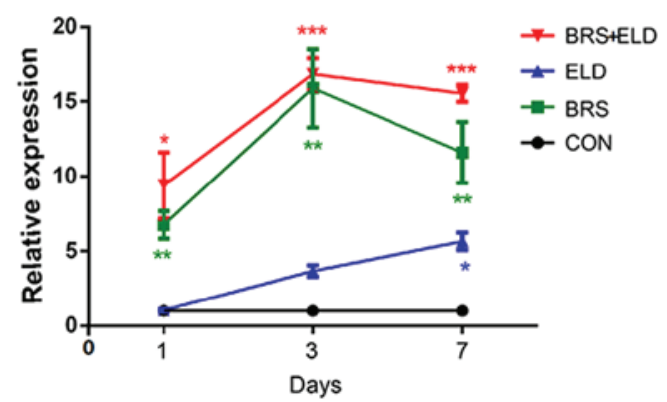

B

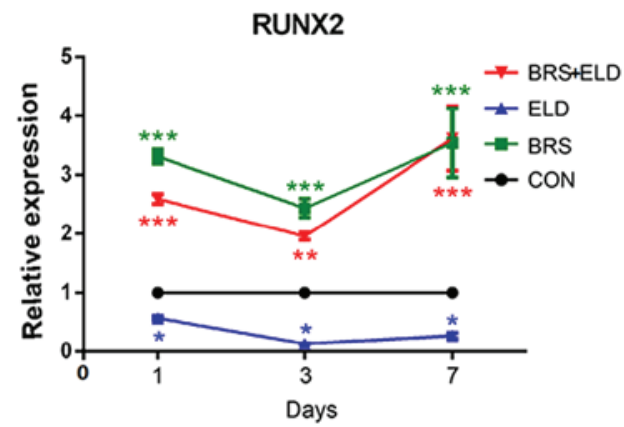

D

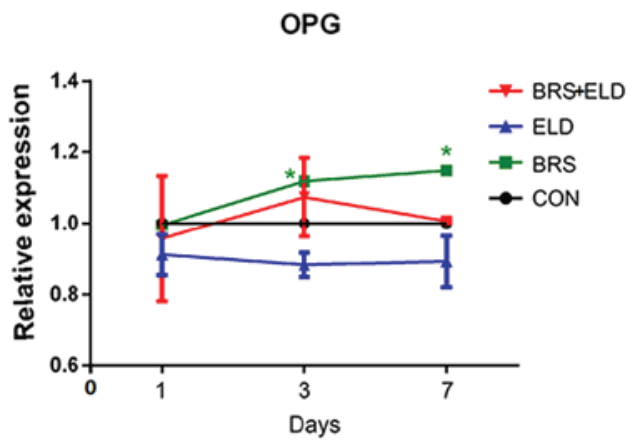

Figure 5. Effect of bone resorption supernatant and ELD on the expression of mRNA of MC3T3-E1 pre-osteoblasts osteogenic markers and RANKL/OPG expressions. Reverse transcription-quantitative PCR analysis of (A) ALP, (B) RUNX2, (C) RANKL, (D) OPG and (E) RANKL/OPG expression in MC3T3-E1 cells cultured in the presence of BRS or ELD and BRS + ELD. ${ }^{*} \mathrm{P}<0.05,{ }^{* *} \mathrm{P}<0.01$ and ${ }^{* * *} \mathrm{P}<0.001$ vs. CON. RANKL, receptor activator of NF- $\kappa \mathrm{B}$ ligand; OPG, osteoprotegerin; ELD, eldecalcitol; ALP, alkaline phosphatase; RUNX2, runt-related transcription factor 2; BRS, bone resorption culture supernatant; CON, control.

osteoblasts in the absence of osteoclasts in vivo. Therefore, in the current study, two distinct osteoblast cell culture models were established in vitro for the assessment of the osteogenic effects without direct osteoclast contact. The aim of the present study was to investigate the hypothesis that complex growth factors produced by active osteoclasts during bone resorption exhibit the potential to regulate the differentiation of osteoblast precursor cells.

The results indicated that RAW 264.7 osteoclast bone resorption supernatant influenced the osteogenic activity of osteoblast-like cells by inhibiting viability and promoting differentiation. However, the RAW 264.7 OCS and ELD exhibited opposite effects. RUNX2 has been demonstrated to promote the expression of major bone matrix protein genes (30), and ALP is a marker of the early stage of osteoblast differentiation (31). A number of studies have indicated that direct effects are exhibited by $1,25-(\mathrm{OH})_{2} \mathrm{D}_{3}$ on osteoblastic cells in vitro (32-34). However, the effect on the viability and differentiation of osteoblastic cells is undetermined. Kurihara et al (33) demonstrated that $1,25-(\mathrm{OH})_{2} \mathrm{D}_{3}$ increases ALP activity in MC3T3-E1 cells in the presence of serum (35). However, Majeska and Rodan (36) reported that in early ROS $17 / 2$ cell cultures, $1,25-(\mathrm{OH})_{2} \mathrm{D}_{3}$ elevates ALP activity, but in later cultures, the steroid reduces ALP activity, indicating that its effect may depend on the differentiation state of cells. Jones (37) indicated that high concentrations of 1,25-dihydroxyvitamin $\mathrm{D}_{3}$ induced the production of analogous compounds, such as $24,25(\mathrm{OH})_{2} \mathrm{D}_{3}$ and $25,26(\mathrm{OH})_{2} \mathrm{D}_{3}$, which compete with 1,25-dihydroxyvitamin $\mathrm{D}_{3}$ to prevent the binding of vitamin $\mathrm{D}$ to its receptors. Therefore, to increase the efficiency of osteoblast differentiation, an adequate concentration of 1,25-dihydroxyvitamin $\mathrm{D}_{3}$ must be maintained for an appropriate time. It has been demonstrated that osteoclasts secrete several potential factors that mediate cell-cell coupling. Kubota et al (26) revealed that RAW 264.7 conditioned culture medium contained the B polypeptide chain PDGF homodimer (PDGF BB), which may suppress osteoblast differentiation in vitro. It has also been demonstrated that PDGF increases osteoblast viability, but reduces ALP activity, mineralized nodule formation and the 

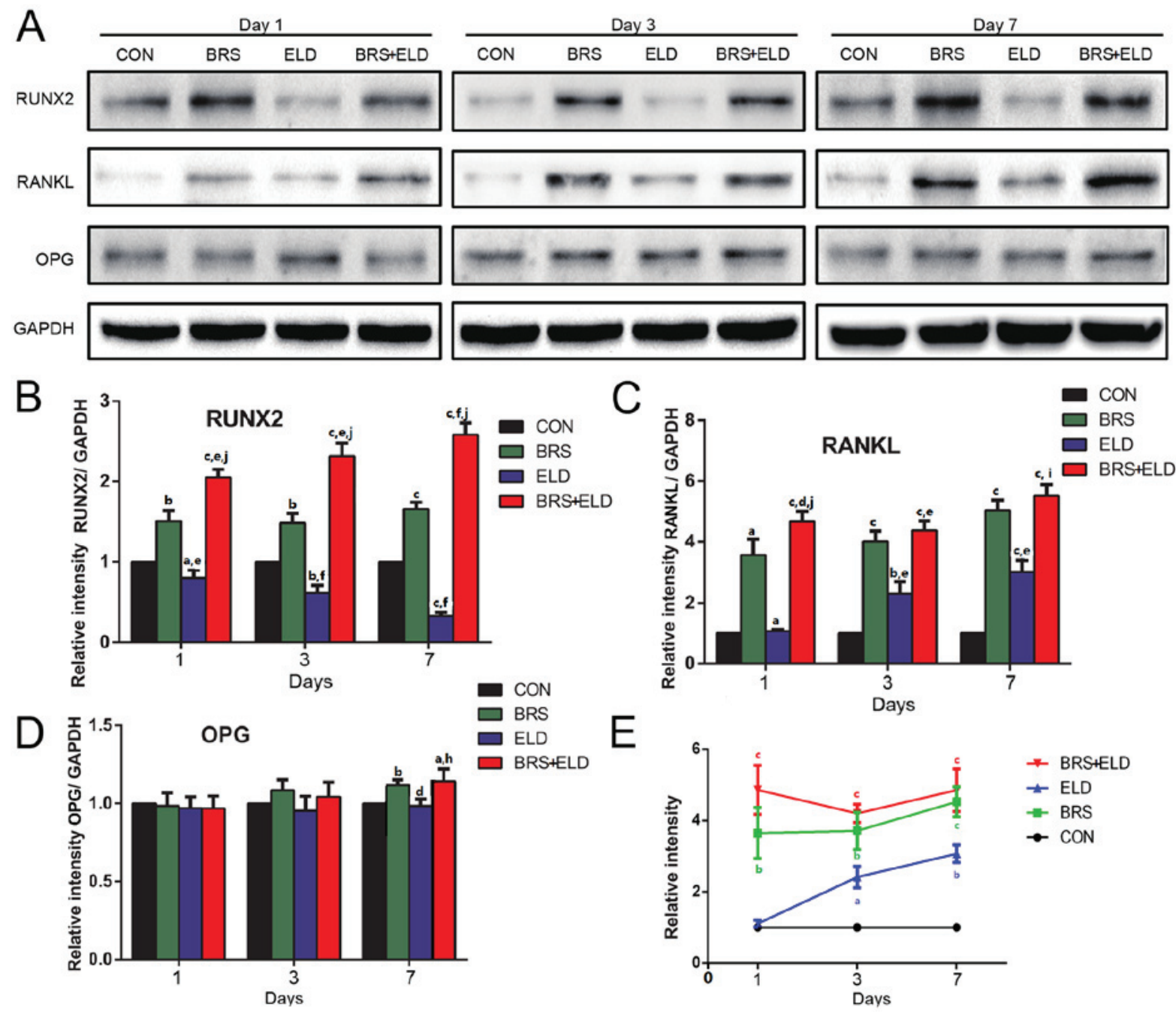

Figure 6. Western blot analysis of pre-osteoblast osteogenic markers and RANKL/OPG expression in MC3T3-E1 cells treated with bone resorption culture supernatant and ELD. (A) Western blot analysis of (A) RUNX2, RANKL, OPG and GADPH expression with subsequent quantification of (B) RUNX2, (C) RANKL, (D) OPG and (E) RANKL/OPG ratio in MC3T3-E1 cells treated with BRS, ELD or BRS + ELD. ${ }^{a} \mathrm{P}<0.05$, ${ }^{\mathrm{b}} \mathrm{P}<0.01$ and ${ }^{\mathrm{c}} \mathrm{P}<0.001 \mathrm{vs}$. CON; ${ }^{d} \mathrm{P}<0.05,{ }^{\mathrm{e}} \mathrm{P}<0.01$ and ${ }^{\mathrm{f}} \mathrm{P}<0.001$ vs. BRS; ${ }^{h} \mathrm{P}<0.05,{ }^{\mathrm{i}} \mathrm{P}<0.01$ and ${ }^{\mathrm{j}} \mathrm{P}<0.001$ vs. ELD. ELD, eldecalcitol; RANKL, receptor activator of NF- $\mathrm{B}$ ligand; OPG, osteoprotegerin; RUNX2, runt-related transcription factor 2; BRS, bone resorption culture supernatant; CON, control.

expression of genes including ALP, osteocalcin and type I collagen $(38,39)$. Sphingosine 1-phosphate (S1P) is produced by osteoclasts and is associated with the S1P receptor expressed on osteoblasts to enhance osteoblast migration and survival as well as RANKL expression (40). It has been demonstrated that molecules secreted from osteoclasts alone are insufficient to initiate osteoblastogenesis (32).

In contrast to the OCS, the supernatant from the osteoclast bone resorption model decreased the viability and enhanced the differentiation of MC3T3-E1 cells (41). The results indicated that the effects of OCS and BRS on the MC3T3-E1 pre-osteoblast viability and ALP activity may be caused by the diversity of the molecules present in these supernatants. Growth factors that are released from the bone matrix, including transforming growth factor- $\beta$ (TGF- $\beta$ ) and insulin-like growth factors (IGF-1), have been considered to be coupling factor candidates $(42,43)$.

Bone remodeling depends on coordination between bone resorption and subsequent bone formation. However, a study has demonstrated that osteoclast bone resorptive activity is dispensable for osteoblastic bone formation (44). Osteoclast ablation in M-CSF (45) or c-fos (46) deficient mice resulted in secondary negative effects on bone formation, in contrast to mutations where bone resorption is abrogated with sustained osteoclast numbers, such as in c-src deficient mice (47). These data indicated that the presence of osteoclasts, rather than osteoblastic bone resorption, is important for the subsequent activation of osteoblasts during bone remodeling (29). However, several in vivo factors should be considered. For example, the topography of the bones surface could affect the osteoblastic bone formation process (48). The systemic anabolic effect of parathyroid, Vitamin $\mathrm{D}_{3}$ and calcium levels serve prominent roles in bone remodeling $(49,50)$. The coordination between osteoclasts and osteoblasts is a multifaceted process, with numerous contributing regulator molecules $(51,52)$. It is unlikely that a single factor dominates during the entire coupling process. Additional data is required to aid in the understanding of the precise coordination mechanism of osteoclasts and osteoblasts during bone remodeling. 
The most prominent signals exhibited from osteoblasts to osteoclasts mainly come from M-CSF and the RANKL/OPG system (32). These signals are essential and sufficient to drive the process of bone resorption and formation and make them tightly coupled (1). In the current study, the effects of medium containing OCS and BRS on the expressions of RANKL and OPG on the mouse osteoblastic cell line MC3T3-E1 was assessed using RT-qPCR and western blot analysis. OCS and BRS enhanced RANKL expression. However, when compared with the CON group, OPG expression of the OCS groups decreased, but was slightly increased in the BRS groups. These discrepancies resulted in the significantly different RANKL/OPG ratio between the OCS groups (fold change $>20$ ) and BRS groups (fold change $<20$ ) when compared with the CON group. The increased RANKL/OPG ratio exhibited by the OCS group demonstrated a positive feedback loop, through which osteoblastic cells attempted to increase the number of osteoclasts in the absence of osteoclasts and a non-bone resorption situation (53). The aforementioned results also revealed that the osteoclastogenic function is continuously being controlled and balanced for bone remodeling, in case of increased bone resorption over bone formation, which leads to bone loss disease.

Despite their osteoclastogenesis effect in vitro, vitamin $\mathrm{D}_{3}$ analogs, including ELD, have been used as therapeutic drugs for osteoporosis $(13,54)$. Currently, it has not been determined as to how vitamin $\mathrm{D}_{3}$ increases bone mineral density via the suppression of osteoclastic bone resorption in vivo. The differences in culture environments without interference from hormones, including $\mathrm{PTH}$ and estrogen, in vitro compared with in vivo may provide an explanation for the substantial discrepancy between in vitro and in vivo effects of vitamin $\mathrm{D}$ compounds on bone resorption (55). In the present study the conditions of the culture medium were applied to determine whether the bone resorption environment influenced the effect of ELD on osteoblasts. These in vitro studies demonstrated that ELD decreases MC3T3-E1 pre-osteoblast viability and differentiation markers ALP and RUNX2, and these results were repeated in previous studies that used the same cell line $(56,57)$. Specific gene modification studies using mice, have revealed that vitamin $\mathrm{D}_{3}$ is not a positive regulator of bone formation (58-60). The positive effect on bone mineralization in vivo, including the regulation of serum calcium levels through the intestine, occurred outside the skeletal tissues $(61,62)$. Additionally, it has previously been clarified that vitamin $\mathrm{D}_{3}$ induces the expression of a variety of pro-osteoclastogenic cytokines, especially RANKL (63). The present study demonstrated that ELD downregulated OPG expression and upregulated RANKL expression, leading to an increased RANKL/OPG ratio when administrated to MC3T3-E1 cells alone or when combined with OCS/BRS media. These results indicated that the culture environment may not be the primary influence of the vitamin $D_{3}$ effect. However, further studies are required to assess the association of ELD concentration and condition media in the action of other osteoblastic cells.

The present study indicated that the molecules secreted by osteoclasts and/or released from the bone matrix exhibited important effects on osteoblast activity. In addition, osteoclast bone resorption supernatant influenced the osteogenic activity of osteoblast cells. However, RANKL expression and the RANKL/OPG ratio of osteoblasts were increased by the treatment of BRS, BRS
+ ELD and OCS + ELD. Eldecalcitol exhibited opposite effects on osteoblastic differentiation and function in the presence or absence of osteoclastic bone resorption. That is, ELD inhibits osteoblastic differentiation in vitro. However, in the presence of BRS, which mimics the local bone microenvironment in vivo, the net effect on osteogenesis was positive. Results observed in the presented study suggest that some substances released in the surrounding microenvironment during bone resorption serve an important role in the anti-osteoporosis effect of ELD.

\section{Acknowledgements}

Not applicable.

\section{Funding}

The present study was partially supported by The National Nature Science Foundation of China (grant nos. 81470719 and 81611140133) to ML and The National Nature Science Foundation of China (grant no. 81771108) to GJ.

\section{Availability of data and materials}

The datasets used and/or analyzed during the present study are available from the corresponding author on reasonable request.

\section{Authors' contributions}

XW and ML conceived and designed the current study. JB and JD performed the experiments, analyzed and interpreted the data; LS, WF and WW gathered data, prepared the figures and drafted the manuscript. JG, TH and HL participated in performing the experiments, edited and revised the manuscript. All authors read and approved the final manuscript to be published.

\section{Ethics approval and consent to participate}

Formal ethical approval and patient consent for this study was not required.

\section{Patient consent for publication}

Not applicable.

\section{Competing interests}

The authors declare that they have no competing interests.

\section{References}

1. Hadjidakis DJ and Androulakis II: Bone remodeling. Ann N Y Acad Sci 1092: 385-396, 2006.

2. Matsuo K and Irie N: Osteoclast-osteoblast communication. Arch Biochem Biophys 473: 201-209, 2008.

3. Tamma R and Zallone A: Osteoblast and osteoclast crosstalks: From OAF to Ephrin. Inflamm Allergy Drug Targets 11: 196-200, 2012.

4. Ueno Y, Shinki T, Nagai Y, Murayama H, Fujii K and Suda T: In vivo administration of 1,25-dihydroxyvitamin D3 suppresses the expression of RANKL mRNA in bone of thyroparathyroidectomized rats constantly infused with PTH. J Cell Biochem 90: 267-277, 2003. 
5. van Driel $M$ and van Leeuwen JP: Vitamin D endocrine system and osteoblasts. Bonekey Rep 3: 493, 2014.

6. Pèrez A, Chen TC, Turner A, Raab R, Bhawan J, Poche P and Holick MF: Efficacy and safety of topical calcitriol (1,25-dihydroxyvitamin d3) for the treatment of psoriasis. Br J Dermatol 134: 238-246, 1996.

7. Guyton KZ, Kensler TW and Posner GH: Cancer chemoprevention using natural vitamin D and synthetic analogs. Annu Rev Pharmacol Toxicol 41: 421-442, 2001.

8. Nishii Y: Active vitamin D and its analogs as drugs for the treatment of osteoporosis: Advantages and problems. J Bone Miner Metab 20: 57-65, 2002.

9. Nishii Y and Okano T: History of the development of new vitamin D analogs: Studies on 22-oxacalcitriol (OCT) and 2beta(3-hydroxypropoxy)calcitriol (ED-71). Steroids 66: 137-146, 2001.

10. Nishii $Y$ : Rationale for active vitamin $D$ and analogs in the treatment of osteoporosis. J Cell Biochem 88: 381-386, 2003.

11. Mano H, Nishikawa M, Yasuda K, Ikushiro S, Saito N, Takano M, Kittaka A and Sakaki T: Development of novel bioluminescent sensor to detect and discriminate between vitamin D receptor agonists and antagonists in living cells. Bioconjug Chem 26: 2038-2045, 2015.

12. Matsumoto T, Miki T, Hagino H, Sugimoto T, Okamoto S, Hirota T, Tanigawara Y, Hayashi Y, Fukunaga M, Shiraki M and Nakamura T: A new active vitamin D, ED-71, increases bone mass in osteoporotic patients under vitamin D supplementation: A randomized, double-blind, placebo-controlled clinical trial J Clin Endocrinol Metab 90: 5031-5036, 2005.

13. Matsumoto T, Takano T, Yamakido S, Takahashi $\mathrm{F}$ and Tsuji N: Comparison of the effects of eldecalcitol and alfacalcidol on bone and calcium metabolism. J Steroid Biochem Mol Biol 121: 261-264, 2010.

14. Hatakeyama S, Yoshino M, Eto K, Takahashi K, Ishihara J, Ono Y, Saito H and Kubodera N: Synthesis and preliminary biological evaluation of 20-epi-eldecalcitol [20-epi-1alpha,25dihydroxy-2beta-(3-hydroxypropoxy)vitamin D3: 20-epi-ED-71]. J Steroid Biochem Mol Biol 121: 25-28, 2010.

15. Uchiyama Y, Higuchi Y, Takeda S, Masaki T, Shira-Ishi A Sato K, Kubodera N, Ikeda K and Ogata E: ED-71, a vitamin D analog, is a more potent inhibitor of bone resorption than alfacalcidol in an estrogen-deficient rat model of osteoporosis. Bone 30: 582-588, 2002

16. Tang Y, Wu X, Lei W, Pang L, Wan C, Shi Z, Zhao L, Nagy TR, Peng $\mathrm{X}, \mathrm{Hu} \mathrm{J}$, et al: TGF-beta1-induced migration of bone mesenchymal stem cells couples bone resorption with formation. Nat Med 15: 757-765, 2009.

17. Weivoda MM, Ruan M, Pederson L, Hachfeld C, Davey RA, Zajac JD, Westendorf JJ, Khosla S and Oursler MJ: Osteoclast TGF- $\beta$ receptor signaling induces Wnt 1 secretion and couples bone resorption to bone formation. J Bone Miner Res 31: 76-85, 2016.

18. Xian L, Wu X, Pang L, Lou M, Rosen CJ, Qiu T, Crane J, Frassica F, Zhang L, Rodriguez JP, et al: Matrix IGF-1 maintains bone mass by activation of mTOR in mesenchymal stem cells. Nat Med 18: 1095-1101, 2012.

19. Engelholm LH, Melander MC, Hald A, Persson M, Madsen DH, Jürgensen HJ, Johansson K, Nielsen C, Nørregaard KS, Ingvarsen SZ, et al: Targeting a novel bone degradation pathway in primary bone cancer by inactivation of the collagen receptor uPARAP/Endo180. J Pathol 238: 120-133, 2016.

20. Boeyens JC, Deepak V, Chua WH, Kruger MC, Joubert AM and Coetzee M: Effects of $\omega 3$ - and $\omega 6$-polyunsaturated fatty acids on RANKL-induced osteoclast differentiation of RAW264.7 cells: A comparative in vitro study. Nutrients 6: 2584-2601, 2014.

21. Lee YS, Kim YS, Lee SY, Kim GH, Kim BJ, Lee SH, Lee KU, Kim GS, Kim SW and Koh JM: AMP kinase acts as a negative regulator of RANKL in the differentiation of osteoclasts. Bone 47: 926-937, 2010

22. Choi SW, Son YJ, Yun JM and Kim SH: Fisetin inhibits osteoclast differentiation via downregulation of $\mathrm{p} 38$ and c-Fos-NFATc1 signaling pathways. Evid Based Complement Alternat Med 2012: 810563, 2012.

23. Livak KJ and Schmittgen TD: Analysis of relative gene expression data using real-time quantitative PCR and the 2(-Delta Delta C(T)) method. Methods 25: 402-408, 2001.

24. Zauli G, Rimondi E, Nicolin V, Melloni E, Celeghini C and Secchiero P: TNF-related apoptosis-inducing ligand (TRAIL) blocks osteoclastic differentiation induced by RANKL plus M-CSF. Blood 104: 2044-2050, 2004
25. Kim MH, Shim KS, Lee SU, Kim YS, Min YK and Kim SH: Stimulatory effect of undecylenic acid on mouse osteoblast differentiation. Phytother Res 24: 559-564, 2010.

26. Kubota K, Sakikawa C, Katsumata M, Nakamura T and Wakabayashi K: Platelet-derived growth factor BB secreted from osteoclasts acts as an osteoblastogenesis inhibitory factor. J Bone Miner Res 17: 257-265, 2010.

27. Tanaka Y, Nakayamada S and Okada Y: Osteoblasts and osteoclasts in bone remodeling and inflammation. Curr Drug Targets Inflamm Allergy 4: 325-328, 2005.

28. Nishiya $Y$ and Sugimoto S: Effects of various antihypertensive drugs on the function of osteoblast. Biol Pharm Bull 24: 628-633, 2001.

29. Toray H, Hasegawa T, Sakagami N, Tsuchiya E, Kudo A, Zhao S, Moritani Y, Abe M, Yoshida T, Yamamoto T, et al: Histochemical assessment for osteoblastic activity coupled with dysfunctional osteoclasts in c-src deficient mice. Biomed Res 38: 123-134, 2017.

30. Komori T: Regulation of bone development and extracellular matrix protein genes by RUNX2. Cell Tissue Res 339: 189-195, 2010.

31. Hoemann CD, El-Gabalawy $\mathrm{H}$ and McKee MD: In vitro osteogenesis assays: Influence of the primary cell source on alkaline phosphatase activity and mineralization. Pathol Biol (Paris) 57: 318-323, 2009

32. Han Y, You X, Xing W, Zhang Z and Zou W: Paracrine and endocrine actions of bone-the functions of secretory proteins from osteoblasts, osteocytes, and osteoclasts. Bone Res 6: 16, 2018

33. Kurihara N, Ishizuka S, Kiyoki M, Haketa Y, Ikeda K and Kumegawa M: Effects of 1,25-dihydroxyvitamin D3 on osteoblastic MC3T3-E1 cells. Endocrinology 118: 940-947, 1986.

34. van den Bemd GJ, Pols HA, Birkenhäger JC, Kleinekoort WM and van Leeuwen JP: Differential effects of 1,25-dihydroxyvitamin D3-analogs on osteoblast-like cells and on in vitro bone resorption. J Steroid Biochem Mol Biol 55: 337-346, 1995.

35. Haneji T, Kurihara N, Ikeda K and Kumegawa M: 1 alpha, 25-Dihydroxyvitamin D3 and analogues of vitamin D3 induce alkaline phosphatase activity in osteoblastic cells derived from newborn mouse calvaria. J Biochem 94: 1127-1132, 1983.

36. Majeska RJ and Rodan GA: The effect of 1,25(OH)2D3 on alkaline phosphatase in osteoblastic osteosarcoma cells. J Biol Chem 257: 3362-3365, 1982.

37. Jones G: Pharmacokinetics of vitamin D toxicity. Am J Clin Nutr 88: 582S-586S, 2008.

38. Centrella M, McCarthy TL, Kusmik WF and Canalis E: Relative binding and biochemical effects of heterodimeric and homodimeric isoforms of platelet-derived growth factor in osteoblast-enriched cultures from fetal rat bone. J Cell Physiol 147: 420-426, 1991.

39. Yu X, Hsieh SC, Bao W and Graves DT: Temporal expression of PDGF receptors and PDGF regulatory effects on osteoblastic cells in mineralizing cultures. Am J Physiol 272: C1709-C1716, 1997.

40. Ryu J, Kim HJ, Chang EJ, Huang H, Banno Y and Kim HH: Sphingosine 1-phosphate as a regulator of osteoclast differentiation and osteoclast-osteoblast coupling. EMBO J 25: 5840-5851, 2006.

41. Chen LL, Wang K, Zhang J and Wu YM: Effect of the bone resorption supernatant from RAW264.7 osteoclast on the osteogenic activity of mouse MC3T3-E1 cell. Zhonghua Kou Qiang Yi Xue Za Zhi 47: 32-37, 2012 (In Chinese).

42. Howard GA, Bottemiller BL, Turner RT, Rader JI and Baylink DJ: Parathyroid hormone stimulates bone formation and resorption in organ culture: Evidence for a coupling mechanism. Proc Natl Acad Sci USA 78: 3204-3208, 1981.

43. Martin TJ and Sims NA: Osteoclast-derived activity in the coupling of bone formation to resorption. Trends Mol Med 11: 76-81, 2005.

44. Karsdal MA, Martin TJ, Bollerslev J, Christiansen C and Henriksen K: Are nonresorbing osteoclasts sources of bone anabolic activity? J Bone Miner Res 22: 487-494, 2007.

45. Sakagami N, Amizuka N, Li M, Takeuchi K, Hoshino M, Nakamura M, Nozawa-Inoue $\mathrm{K}$, Udagawa $\mathrm{N}$ and Maeda $\mathrm{T}$ : Reduced osteoblastic population and defective mineralization in osteopetrotic (op/op) mice. Micron 36: 688-695, 2005

46. Grigoriadis AE, Wang ZQ, Cecchini MG, Hofstetter W, Felix R, Fleisch HA and Wagner EF: c-Fos: A key regulator of osteoclast-macrophage lineage determination and bone remodeling. Science 266: 443-448, 1994.

47. Soriano P, Montgomery C, Geske R and Bradley A: Targeted disruption of the c-src proto-oncogene leads to osteopetrosis in mice. Cell 64: 693-702, 1991 
48. Gray C, Boyde A and Jones SJ: Topographically induced bone formation in vitro: Implications for bone implants and bone grafts. Bone 18: 115-123, 1996.

49. Kalu DN, Doyle FH, Pennock J, Denys-Matrajt H and Foster GV: Anabolic effect of parathyroid hormone on bone in the rat. Calcif Tissue Res (Suppl): S72, 1970.

50. Baldock PA, Thomas GP, Hodge JM, Baker SU, Dressel U, O'Loughlin PD, Nicholson GC, Briffa KH, Eisman JA and Gardiner EM: Vitamin D action and regulation of bone remodeling: Suppression of osteoclastogenesis by the mature osteoblast J Bone Miner Res 21: 1618-1626, 2006.

51. Schwarz P, Brixen KT and Mosekilde L: Calcium homeostasis and normal bone remodeling. Ugeskr Laeger 167: 871-873, 2005 (In Danish).

52. Sanchez-Fernandez MA, Gallois A, Riedl T, Jurdic P and Hoflack B: Osteoclasts control osteoblast chemotaxis via PDGF-BB/PDGF receptor beta signaling. PLoS One 3: e3537, 2008.

53. Lotinun S, Kiviranta R, Matsubara T, Alzate JA, Neff L, Lüth A, Koskivirta I, Kleuser B, Vacher J, Vuorio E, et al: Osteoclast-specific cathepsin $\mathrm{K}$ deletion stimulates S1P-dependent bone formation. J Clin Invest 123: 666-681, 2013.

54. Noguchi Y, Kawate H, Nomura M and Takayanagi R: Eldecalcitol for the treatment of osteoporosis. Clin Interv Aging 8: 1313-1321, 2013.

55. Suda T, Takahashi $\mathrm{F}$ and Takahashi N: Bone effects of vitamin D-Discrepancies between in vivo and in vitro studies. Arch Biochem Biophys 523: 22-29, 2012.

56. Shi YC, Worton L, Esteban L, Baldock P, Fong C, Eisman JA and Gardiner EM: Effects of continuous activation of vitamin $\mathrm{D}$ and Wnt response pathways on osteoblastic proliferation and differentiation. Bone 41: 87-96, 2007.

57. Chen YC, Ninomiya T, Hosoya A, Hiraga T, Miyazawa H and Nakamura H: 1 $\alpha, 25$-Dihydroxyvitamin D3 inhibits osteoblastic differentiation of mouse periodontal fibroblasts. Arch Oral Biol 57: 453-459, 2012
58. Tanaka $\mathrm{H}$ and Seino Y: Direct action of 1,25-dihydroxyvitamin $\mathrm{D}$ on bone: VDRKO bone shows excessive bone formation in normal mineral condition. J Steroid Biochem Mol Biol 89: 343-345, 2004

59. Yamamoto Y, Yoshizawa T, Fukuda T, Shirode-Fukuda Y, Yu T, Sekine K, Sato T, Kawano H, Aihara K, Nakamichi Y, et al: Vitamin D receptor in osteoblasts is a negative regulator of bone mass control. Endocrinology 154: 1008-1020, 2013.

60. Nakamichi Y, Udagawa N, Horibe K, Mizoguchi T, Yamamoto Y, Nakamura T, Hosoya A, Kato S, Suda T and Takahashi N: VDR in osteoblast-lineage cells primarily mediates vitamin D treatment-induced increase in bone mass by suppressing bone resorption. J Bone Miner Res 32: 1297-1308, 2017.

61. Amling M, Priemel M, Holzmann T, Chapin K, Rueger JM, Baron R and Demay MB: Rescue of the skeletal phenotype of vitamin D receptor-ablated mice in the setting of normal mineral ion homeostasis: Formal histomorphometric and biomechanical analyses. Endocrinology 140: 4982-4987, 1999.

62. Lieben L and Carmeliet G: The delicate balance between vitamin $\mathrm{D}$, calcium and bone homeostasis: Lessons learned from intestinal- and osteocyte-specific VDR null mice. J Steroid Biochem Mol Biol 136: 102-106, 2013.

63. Lee SK, Kalinowski J, Jastrzebski S and Lorenzo JA: 1,25(OH)2 vitamin D3-stimulated osteoclast formation in spleen-osteoblast cocultures is mediated in part by enhanced IL-1 alpha and receptor activator of NF-kappa B ligand production in osteoblasts. J Immunol 169: 2374-2380, 2002.

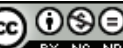

This work is licensed under a Creative Commons Attribution-NonCommercial-NoDerivatives 4.0 International (CC BY-NC-ND 4.0) License. 